employed has considerable and striking advantages over the others. It is easy to perform, rapid in its execution, and has the advantage, possessed by none of the others, that one can see exactly how much of the wall of the stomach is being included; all the sutures can be passed before any one is tied, and, finally, it brings into apposition the walls of the stomach in a way best calculated to produce firm adhesions. The roll which projects into the cavity of the stomach is mach smaller than might be anticipated and has, I should

FIG. 2.

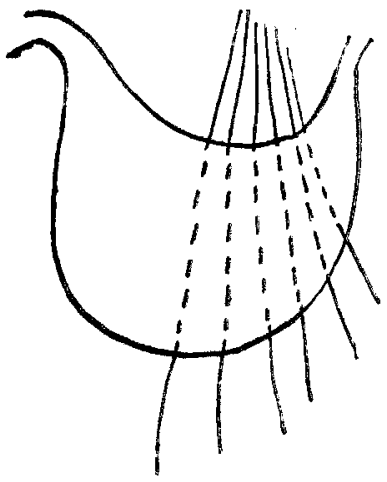

Diagram ill ustrating the method of introducing stitches.

suppose, none of the possible disadvantages possessed by the long, flaccid, and pendulous folds produced in other operations. The abdominal incision in Bircher's and Brandt's operations was made patallel to the costal margin. In Bennett's case and in mine a medium incision was employed.

Snch then, is the operation of gastrorrhaphy or gastroplication. It is a procedure which, so far as one can judge from the scant material at hand, is likely to have a certain range of usefulness when employed in suitable cases. What the nltimate position of the operation in surgery will be it is at this early period quite impossible to say. There are many points upon which we require more precise and more accurate information before a trustworthy and reliable decision can be arrived at. We must learn the frequency of the condition of atonic dilatation, so-called, of cases, that is, of enlargement of the stomach where the symptoms are due, not to any catarrhal or other organic disease in the walls of the viscus, bat merely to the bigness of the organ, and where medical treatment has proved of little or no avail. Upon this point the physicians are the most competent to pass an opinion. It will be for them to say when, and in what case, a procedure of this sort is likely to be useful. We must so far as is possible guard against operative interference in cases not wholly suitable. In one case, at least, amongst the few already recorded there was an ulcer with some thickening at the pylorus and no very great distension of the stomach.

In judging of the mortality we cannot place any reliance upon statistics based on so few cases, but it is only reasonable to suppose that as the time occupied by the operation is brief, and as little or no material damage is done to any organ, the risks cannot but be very slight.

As regards permanence of relief there is again very little evidence upon which to base one's judgment. The only case of recurrence of symptoms is that under $\mathbf{M r}$. Bennett's care already mentioned. What seems most striking on reading the records of these cases is the immediate relief from the severe and most disabling symptoms which is invariably observed; whether such relief is permanent is a question which can only be answered in the future; but I think we may fairly argue that the more permanent the adhesions we produce by the operation we select the more likely are we to secure prolonged or possibly complete and lasting relief. The operation is as yet only in a tentative stage and it is solely for the purpose of calling attention to it as a procedure with some arguments to recommend and facts to justify and support it that I have ventured to introduce the subject.

Leeds.

Drainage of Tadnton.-At a special meeting of the Taunton Town Council held recently it was decided to adapt the present Taunton sewage works to the septic tank system and to apply for sanction for a loan of $£ 18250$ for carrying out these works.

\section{ACUTE ATROPHY OF THE LIVER.}

By WILLIAM O'NEILL, M.D. ABERD., M.R.C.P. LOND, IATR PHYBICTAN TO THE IINCOLN GENERAL DISPENSARY AND TO THE LINCOLN LUNATIC ASYLUM, ETC.

WITH kind permission I would mention in THE LANCET a case of acute atrophy of the liver, or, as the disease is sometimes called, fatal or malignant jaundice, which came ander my care some little time ago.

On Nov. 16th, 1897, I was requested to see a respectable married man, aged forty-six years. He was tall and slender and up to this illness he had not required medical advice since he consulted me sixteen years previously for some slight ailment. He was abstemious and correct in his mode of living and fortunate in having little or no anxiety on his own account or on that of his family. His house, which was rather small, was pleasantly situated and the drainage of the premises was very good. I found that the patient was slightly jaundiced and in a state bordering on collapse. He complained of headache, nausea, and vomiting, but more especially of an intense pain in the hepatic region. I ascertained that the temperature was below normal and that the pulse was small and weak and about sixty beats in the minute. The tongue was furred, the bowels were confined and the urine was scanty and contained some bile. There was no distension of the abdomen and he only felt tenderness when I pressed my fingers under the right ribs. The illness began on the 13th with chilliness and headache, followed by sickness of the stomach, pain in the right side, some yellowness of the skin, and rapid loss of strength. On the 12th the patient had spent the greater part of the day in laying down oilcloth on his kitchen floor and his wife thought that he had caught cold in so doing owing to the frequent opening of the back door, which admitted currents of cold air. The patient was ordered a stimulant and anodyne draught in effervescence, hot fomentations to the painfal part, and injections of warm water, which brought away dark-coloured evacuations. The next morning I found that the pain and sickness of the stomach had subsided and the patient expressed himself as feeling so well and comfortable that a speedy restoration to health was confidently anticipated by himself and family and it was proposed that on the following Sunday thanks should be offered up in church in gratitude for the quick relief he had obtained from his great sufferings. His mind was quite clear, but his manner was more excitable than usual and the yellow colour of the skin had increased a little in intensity. The temperature was normal and the pulse was good and abont 70 to the minute. On examining the abdomen I discovered that the liver was much smaller and the spleen was considerably larger than in health. A dose of a purgative saline mixture with ammonia was directed to be given every three hours, but few doses of it were taken. In the course of the evening the patient began to wander in his mind and to be drowsy. The delirium and drowsiness increased during the night and on the following morning he was lapsing into deep coma. The coma becoming profound he passed quietly away without having been convulsed in the slightest degree. Two hours before the ratient's death the temperature had risen to $104^{\circ} \mathrm{F}$, and the pulse was very quick and irregular.

The interesting points in this case were the short duration of the disease, which barely exceeded five days, and the great intensity of the pain in the hepatic region, which so resembled the pain caused by the passing of gall-stones that on my first seeing the patient I thought this might be the case. The following morning, however, although he felt better and appeared to be so to his family, I began to suspect the possibility of the development of a more serions state of things than I had apprehended the evening before and my suspicions were strengthened when I discovered that the liver was shrunken and that the spleen was larger than normal. When the symptoms of coma set in there could be no longer any doubt about the nature of the disease and the result to be expected.

It is evident that acute atrophy of the liver is a general disease in which all the organs of the body suffer more or less as well as the liver and in all probability microorganisms of a malignant character are the exciting cause of the malady. In the above case the wind coming in through the back-door or the effluvium arising from the oilcloth may have been carriers of the microbes, which could 
easily enter the body through the medinm of the lungs. But whatever the noxious poison was, the effects, especially toward the end, resembled, to my mind, those of opium poisoning with the exception that opium contracts the pupils of the eyes whereas in this case the pupils were widely dilated.

Shrinking of the liver in connexion with fatal jaundice was noticed as far back as 1826 by Dr. Allison of Edinburgb and a few years afterwards by Dr. Bright of London, and subsequent]y to this the same pathological appearance was observed by Dr. Graves of Dablin. In 1840 an interesting account of three cases of this disease was sent by Dr. Hanlon of Portarlington, Ireland, to Dr. Graves. The three patients were sisters, the oldest of whom was seventeen years of age and the youngest eight years of age. The two elder patients died comatose and the youngest recovered, a very unusual occurrence in this disease. In $1845 \mathrm{Mr}$. Busk and Dr. George Budd examined microscopically a liver that was taken from a man who died from fatal jaundice in the Seamen's Hospital and the appearances they noticed were much the same as those described by modern observers. But shrinking of the liver is not a necessary or constant pathological appearance in fatal jaundice. In 1891 a case came under my observation in which the liver was much larger than normal. The patient was a stout woman, aged forty years, who had suffered a long time from disease of the heart of an obstructive character. The abnormal size of the liver was caused, I think, by the diseased heart, and it may be that the congested state of the liver prevented its shrinking, which it might have done if the disease of the heart had not existed. The woman, who had an enlarged spleen, died comatose about a week after the jaundice set in. Neither of the foregoing patients presented any indication of hæmorrhage, but I remember a case of fatal jaundice in which it was a formidable complication. The patient was a fat, fair haired woman of about forty-six years of age, who after a severe wetting and prolonged exposure to cold was seized with pain in the right side, followed by vomiting and other severe symptoms and jaundice. To relieve the pain leeches were applied and when they had fallen off the bleeding continued and could not be effectually stopped; then followed hæmorrhage from the bowels and stomach and patches of ecchymosis appeared on the skin and also an innumerable number of small spots of blood extravasation resembling fleabites. Soon after the bleeding set in the woman lapsed into coma, in which state she died after an illness that did not exceed ten days.

Fatal jaundice is one of the rarest diseases in this country with which the physician has to contend, and happily for his peace of mind that this is so, for in his encounter with it he hardly ever comes off victorious. It may therefore be conjectured that the treatment of the malady is most disappointing. Treatment can relieve pain and suffering it is true, and this in itself is a great boon to the sufferer, but it is, I think, nearly futile in arresting that downward course which ends in Sheol. Saline purgatives, quinine, mineral acids, and astringents when bleeding takes place have been recommended. But from the nature of the disease what we want is some ingredient which would grapple with, and render innocuous, the microbes or other noxious matters circulating in the blood.

Lincoln.

\section{THREE UNUSUAL CASES OF RENAL} CALCULUS. ${ }^{1}$

By WILLIAM HENRY BATTLE, F.R.C.S ENG.,

AFSISTANT 8URGEON TO ST. THOMAS'S HOSPITAL AND SURGEON TO THE ROYAL FREE HOSPITAL.

I HAVE thought that a short account of some unusual cases of renal calculus would be of interest to the Fellows of the Medical Society of London and have selected three from amongst those which have been under my care during the past year or so. The surgeon is fo frequently called apon at the present time to perform the operation of nephrolithotomy tbat the account of an ordinary case is no lorger of interest excepting to the surgeon himself and the patient who is relieved of the stone. The cases which I have 1 A paper read before the Medical Society of London on April 25th, selected are as follows: (1) a case in which constant hæmaturia, although the patient was lying in bed, had persisted for some time unaccompanied by pain of a natare to permit of our diagnosing the site of the calculus; (2) one in which some pain in the kidney had persisted for ten years without renal colic but in which the symptoms made diagnosis easy ; in this case the stone was of unusual formation ; and (3) a case of acute pyonephrosis due to obstruction of the ureter, in which nephrotomy was required and a stone removed, subsequent exploration of the ureter performed, and later a pultaceous mass expelled per urethram after which the lumbar wound closed.

CASE 1.-A woman, aged forty-four years, was admitted to the Royal Free Hospital under the care of Dr. Calvert on Jan. 4th, 1894. Five years before she had undergone abdominal section for the removal of nterine appendages, but otherwise, with the exception of symptoms of cardiac trouble, she had had nothing notewortby in the way of illness. Six weeks before admission she had had a more severe attack of pain in the region of the heart than ever before and a month ago she had noticed blood in the arine. It was dark in colour and there was a little pain after micturition. This had continued unchanged notil admission. On admission she had pain and tenderness over the cardiac area with evidences of hypertrophy of the heart and disease of the mitral valves. The urine was of a dark red colour and was acid with a specific gravity of 1014 ; it contained blood bat no pus cells, casts or crystals. The patient said that there was some pain on both sides of the spine in the lumbar region and she complained of tenderness on pressure over both kidneys, but the kidneys could not be felt nor was there any difference in the amount of resistance on the two sides, I saw the patient for the first time with Dr. Calvert on March 1st. There had been little change in the state of the urine since her admission to the hospital althongh she had been kept in bed all the time. The urine had been acid and uniformly of a dark red tint. Many examinations had been made and although the quantity of blood corpuscles found did not quite account for the amount of colouration of the urine there was no doubt of their presence and in addition a varying amount of pus had been observed from time to time. Fxaminations for tabercle bacilli had yielded a negative result. She admitted that during some months she had suffered on and off from backache, but affirmed that this had not been more marked on one side of the spine than on the other. I recommended operation, but the patient did not agree to it, and a trial of hammamelis was made but without appreciable effect on the bleeding until the dose had become about a drachm three times daily, when the urine cleared somewhat. Daring the next few days she had a good deal of backache and stated that the pain invariably began if she turned on her left side and started in the right side, being relieved if she turned on the right side or on her back. Before she gave consent to the operation, which was performed on July $7 \mathrm{th}$, there had been but little improvement in the condition of the urine, although for a time the amount of blood passed appeared to almost disappear under the use of the hammamelis. The state of the heart was better, the pulse becoming more regular and less rapid, whilst there was less complaint of pain. Ether was administered and the operation was well borne. An incision was made through the old scar in the middle line and the kidneys were explored. The right one was larger than the left and contained a hard substance in its pelvis. The abdominal wound was therefore temporarily closed, the patient turned on the left side and a stone removed from the right kidney through the loin in the asual manner. The substance of the kidney on its posterior aspect close to the pelvis was incised and the finger was inserted. The stone, which was very irregular, with one branch running at right angles to the main part and posteriorly, was extracted with some difficulty as the forceps frequently slipped in consequence of the crumbling of a layer which covered the surface. Altogether it measured about $2 \frac{1}{2}$ in. in circum. ference and was composed of a hard dark mass covered with a softer, greyish, friable layer of phosphates. The main portion was oxalate of lime. The upper part of the kidney pelvis was dilated, but no change in the lining of the pelvis was apparent to account for the bleeding. The wounds were then closed, a drainage-tube being inserted into the lumbar one. The left kidrer was apparently normal. The weight of the calculus was $116 \frac{1}{2}$ grains.

Recovery was slow although there was nothing notewortby as to the manner in which the wounds closed. At the end of a fortnight there were no blood corpuscles to 